\title{
The Sea-Bird as an Individual: Results of Ringing Experiments*
}

\section{By R. M. Lockley, Skokholm Bird Observatory}

CKOKHOLM ISLAND lies a few miles off the $D$ coast of Pembrokeshire. It is about 240 acres in extent, is entirely rock-bound, and has only two houses on it, a lighthouse at the most westerly point, and this is a mile from my own house on the east side of the island. The cliffs are of Old Red Sandstone, and there is a good thick soil on the greater part of the island.

I was attracted to the island in the first place by its great wealth of sea-bird life. Later, as opportunity afforded, I commenced to look into the individual lives of these birds. The first essential in such a study, since individual sea-birds of one species are more exactly alike than peas in a pod, was some method of marking. I adopted Mr. Witherby's scheme for marking birds with numbered leg-rings. This scheme has now been taken over by the British Trust for Ornithology and is housed in the British Museum (Natural History).

There are seven sizes of rings to suit all species of British birds from a wren to an eagle. Each ring has a serial number and the inscription "Inform British Museum (Natural History), London" ; so that those who capture alive or find dead a bird with such a ring will know what to do in the interests of scientific bird-study.

I started my study of the individual sea-bird with the Manx shearwater (Puffinus puffinus puffinus (Brünn.)), the habits of which were at that time very little known. There are probably ten thousand pairs breeding on Skokholm. The shearwater nests in a hole in the ground, sometimes deep in a rabbit-hole, but it will also excavate a hole for itself in soft ground. A small colony nested in shallow burrows within a few yards of my back door. So it was not difficult for me to trace with a stick the winding of the burrow to the nesting recess at the end, and to cut out a turf immediately above the nest, and then to use that turf as a convenient inspection lid.

By degrees my wife and I were able to work out something of the Manx shearwater's lifehistory. The burrow would be inhabited so early in the year as February, the paired birds meeting each dark night as if they were determined to make sure of their nesting territory for another season, although the egg would not be laid until late April or May. Ringing has since shown us that the old breeders always arrive first.

* From a Friday evening discourse delivered at the Royal Institution on November 18.
Sexes are indistinguishable in the field, but in some cases we knew the female by finding her on a new-laid egg. In any event both birds were ringed. Only one egg is laid, and incubation is equally shared. Thus the male, for example, would spend two, three or four days on the egg without quitting the burrow. Then the female would take over. On dark nights, the bird at sea would return and converse with the sitting bird for an hour or two, but would not necessarily relieve it. Nor could we get any evidence that it fed its sitting mate. We came to the conclusion that the sitting bird stuck to the egg as long as hunger permitted, or as long as it could retain possession of the egg against its mate's determination to brood it. This at least appears to be the explanation of the irregular shifts or watches by one or other of the pair on the egg on dark nights.

On moonlit nights, however, this ardour to incubate was cooled by what we presume must be the bird's fear of being seen and killed by the many predatory gulls and hawks which frequent the island. So when a period of moonlit nights intervened, the bird at sea never visited the bird on the nest. Thus for five, six, seven, and more rarely up to ten, and once twelve, nights and days when the moon happened to be near or at the full, and the skies cloudfree, the sitting bird remained brooding but starving at the nest. We even weighed some of these starving birds and proved an average loss of a very small fraction of an ounce every twenty-four hours. Starving is really the wrong word, though at the time it seemed appropriate enough. Now we have found that a sea bird can easily endure long fasts, and no doubt this fact will help us to understand how the sea-bird rides out long storms at sea, when the weather conditions are such that feeding may be impossible and the bird's energies may have to be directed entirely to fighting the storm.

The incubation period of the shearwater we found to be a record for a British breeding bird-fifty to fifty-four days. One parent remained in the burrow by day to brood the downy chick for the first week of its existence; but afterwards the chick was only visited by night. When the moon was bright at night, the same thing happened as during incubation-the burrow was not visited at all. The young chick thus early had its first lesson in fasting. However, it was fat from the day of its birth, and showed no perceptible sign of going back during the occasional enforced fasts ; in fact 
it seemed simply to sleep and, so to speak, consolidate the position already gained. At any rate, this programme of cramming interspersed with an occasional fast results in the chick becoming enormously fat by the time it is sixty days old. To our surprise, we now found that the parents deserted the chick. They had spent sixty days gathering fish for it and many nights of feeding it with the result of that gathering, from a supply of semi-digested food stored in the parental crop. Now suddenly and completely they gave all this up. They went off to sea and certainly would not appear on the Island again until the following spring. We can surmise, if we like, that the physiological state immediately preceding the autumn moult has something to do with this, to us, rather unnatural desertion of the tender nestling. Yet if it seems unnatural, it is at least not improvident. At this age the chick was so fat that it could scarcely waddle to the sea. If it did so and plunged over the cliffs it would drop and go to pieces on the rocks below.

But after nearly a fortnight of fasting, the fledgling is fully feathered and has very little down visible. It takes off for the sea at night, blundering along on all fours, using wings and legs and beak to scramble over rough ground, for it cannot fly yet. When it reaches the cliffs, it is now light enough to flap down on a long plane and so avoid the rocks below.

Once in the sea the young bird is safe. We have taken shearwaters at this stage and put them in the sea by day. How thirsty they were-I wonder if thirst may not be for them an important factor in drawing them to the sea, the sound of which they must hear before they leave the nest. At any rate, their first action is to drink, then to wash ; then suddenly they discover that they can dive. They half-open their wings so that the quills remain partly spread, like a half-opened fan, and with these strong paddles they swim under water with the agility of penguins. They come up for air, and dive again, and so gradually work off to sea, apparently making haste to leave behind the land, of which they have perhaps unpleasant memories of hunger and thirst.

Although we have ringed these young birds, for the time being we have lost them as individuals. But not for long. Recoveries at sea of some of these ringed birds prove that the shearwater has a winter haunt as far south as the Bay of Biscay.

We find that the old breeding birds return faithfully to their nesting burrows early in the spring, and ringing proves that the same individuals pair for another season, probably for life. The breeding bird has built up an association of memories-I scarcely like to call them visual memories in view of the fact that some of the most important events take place in the pitch blackness of the burrow-which lead it back to the same burrow. It must lose contact with its mate at times at sea in winter, possibly altogether. I do not know. But at least the nest is the focal point, the well-remembered place of meeting, and, allowing for frequent gaps caused by death, we have proved by means of ringing that the shearwater pairs for life.

You may ask, what about the young bird? Does it, too, in succeeding years return to the nesting burrows in one of which it was reared ? So far we have not recovered a young bird in the immediate neighbourhood of its birthplace. But it is obvious that in order to keep up the numerical strength of the species a great many young birds must return to breed on the island. It is interesting to speculate as to whether they are guided to the island in the spring by the movements of the adults or by memories of fledging days. Possibly both these factors operate, and the young bird gradually builds a fresh association of memories during preliminary visits to the island. It discovers an empty crevice or hole one night and finds a mate, or more properly I should say a sweetheart, and plays at housekeeping. Next year it will return to this spot, search for or dig a more suitable hole, and start a home in earnest.

To return to more definite information. At present we have adult shearwaters under observation which bred with us for three and four and five years running, and there are two individuals which have bred seven years running. Allowing that the shearwater does not breed until nearly two years old, we thus have individuals five, six, seven and nine years old. So that in time we may well be able to work out the average duration of life of this species.

We have conducted some experiments with ringed sea-birds in an attempt to learn something more of their reputed homing power. An adult shearwater was taken from its egg on Skokholm and released at Start Point in Devon, which is about 200 miles from the island by the sea-route around Cornwall, or 125 miles overland as the crow flies. When released it flew low over the waves, making for sea. It did not attempt to rise up and strike overland in a bee-line for the island. Yet that bird was back on its egg at Skokholm within ten hours. So that if it continued by the sea-route it must have flown steadily at twentytwo miles per hour. Of course its speed by this sea-route must have been much greater, since a shearwater normally does not travel in a straight line, but has a curving, deviating flight, and probably it paused to drink if not to feed.

Two birds released at Frensham Ponds, Surrey, 
performed a similar feat and were back at their nests the following night; but in this case before reaching the sea after release these birds had to cross forty miles of land. But land masses interposed between shearwaters and the sea do not seem to disturb the homing faculty. Shearwaters released inland at Birmingham, Evesham and Manchester, as well as at Limerick in Ireland, have safely homed to Skokholm, though not with the rapidity of the Start Point and Frensham releases. Other birds released in the Firth of Forth and as far north as the Faeroe Islands, and as far south as France and north Spain have also got back to their nests on Skokholm in varying times.

All these homing experiments were within, or (in the case of the inland releases) bounded by, the known sea-range of the species. We needed to go farther afield and see what would happen to birds released outside that range. The farthest distance by sea which we could easily arrange for without transport hardships for the birds (for we wished to be sure they were in good condition for a long flight), was Venice, approximately 3,700 miles from Skokholm via the Adriatic and the Straits of Messina and Gibraltar. Two shearwaters from separate nests were sent, by courtesy of Imperial Airways, to Venice, the distance by air being a little less than one thousand miles. So far as I know the Manx shearwater does not enter the Mediterranean, and therefore is not found in the Adriatic. Certainly ringing has so far proved that our Skokholm birds in their winter wanderings do not go beyond the Bay of Biscay. One of these two shearwaters is an individual of some interest to us, for it has returned to its burrow on Skokholm for five consecutive summers. It had already returned safely from Frensham. Now it returned from Venice in fourteen days. It is impossible to say whether it found its way out through the Straits of Gibraltar, or whether it made a bee-line straight over the Alps, or whether it crossed the backbone of Italy and then over the Pyrenees to the Bay of Biscay. The other shearwater may have returned from Venice in that summer; but we did not catch it until the next spring, when it was back at its usual nest.

These experiments have proved a remarkable homing ability, but we have still nothing but theories to explain it, and the physiological mechanism remains obscure.

We have made similar studies of individuals of other species of sea-birds; the storm-petrel, Hydrobates pelagicus (L.), for example, which breeds in numbers in the rock crevices and old farm-walls of Skokholm. In a similar study of individuals it has shown a life-history not unlike that of its cousin, the shearwater : nocturnal on Jand - a long incubation period of 38-40 days-- and an average fledging period of 61 days. The chick is deserted in the end, and flies off to the sea on its own when sufficiently thinned down from its over-fat nestling stage. The storm-petrel is more nervous and difficult to observe than many sea-birds ; but we have individuals on our books that have been breeding four years with us in the same crevice.

Our ringing study of the puffin, Fratercula arctica graboe (Brehm), enabled us to discover several new facts : an incubation period of 40 days and a fledging period of 49 days. Also the surprising truth that this bird too is deserted by its parents, although other members of the auk family to which it belongs, the razorbill and the guillemot, feed and accompany their chicks at sea when these leave the rocks where they were hatched. The puffin follows the petrel family in deserting its single chick; but this desertion, as with the petrel family, is a wise provision. The young puffin is often reared in burrows some distance from the edge of the cliffs, and so has a long walk to get to that edge, and during that walk it would be exposed to the attacks of predatory gulls and hawks. The puffin chick is full-grown and very fat when it is deserted by its parents. It certainly needs a fast of a week or so to make it light enough to take off without fear of crashing on the rocks below the cliffs. So the young puffin solves two problems, the problem of its excessive weight, and the problem of the predatory gull, by starving for some days before selecting a dark night for its lonely and unseen but momentous stroll to the cliff edge, where it takes the plunge to that friendly element, the sea.

I have spoken of ringing large numbers, even thousands, of sea-birds, and it may be wondered how it is possible for one person to do this and keep account of so many individual birds from year to year. When I began this study of the individual sea-bird I had only my wife's help, and very valuable this was. But we should scarcely have been able to carry on this work as well as our normal duties had we not received encouragement from outside, an encouragement which we were most grateful to have. In the last few years other students have come along, until a voluntary organization has grown under the name of Skokholm Bird Observatory. It is now so organized as to permit us to endeavour to ring every breeding bird on Skokholm, from a rock-pipit to a gull, and to the gannets of Grassholm. We also catch many migratory birds which use the island as a temporary resting place. For example, we ringed in 1938 more than six thousand birds of sixty-one species. This is a figure comparable with figures achieved by subsidized observatories in foreign countries. In Germany and Italy and the United 
States, ornithological work of this nature is recognized officially as having an educational and scientific value, and it is blessed with the practical support of the Government concerned. Here in Britain ornithology outside museums depends entirely on voluntary support. So that the running of an observatory on a remote island is not without its anxieties in more than one direction. Rings at three-farthings each add up to a considerable figure in one year, and there is a very large amount of clerical work in the recording and card-indexing of thousands of individual ringed birds. Nevertheless, this voluntary organization is being carried on for the present, and is about to issue its third modest annual report.
Finally, it may be suggested that catching and handling birds must disturb them unduly. On the contrary, by gentle handling many birds have become so used to us that they are almost tame, as tame, in fact, as wild animals are in nature reserves where they have learned that no harm will come to them from human beings. Indeed if the birds were not reasonably tame, it would be impossible to study them individually. This way of studying birds by ringing them is a good deal better than the old way of studying them by means of the gun and the collecting box. Ringing establishes a new kind of contact, a sort of friendly conspiracy with the living bird.

\section{British Empire Cancer Campaign}

$\mathrm{T}$ HE fifteenth annual report of the British Empire Cancer Campaign was presented at a meeting held at the House of Lords at the end of November. The Duke of Gloucester, as president, announced at the meeting that a new cancer research centre of the Campaign was to be established at the University of Oxford and a grant was voted for the work to be carried on at this new centre. During the last year, $£ 50,000$ was expended by the British Empire Cancer Campaign on research mainly in Great Britain. Ten years ago the corresponding annual expenditure was only $£ 20,000$.

During the past year a considerable amount of work has been carried out on the biological effects of radiations. Mr. H. Burrows, Dr. W. V. Mayneord and Dr. J. E. Roberts have found that the exposure of inflamed tissue in the groins of rabbits to $\mathrm{X}$-rays $(600 \mathrm{r}$.) produced malignant tumours in eight out of nine rabbits. Dr. J. C. Mottram has examined the effect of combined treatment with the carcinogenic hydrocarbon, $3: 4$-benzpyrene, and gamma radiation. Doses of 160-1440 r. increase the carcinogenic action of the benzpyrene, while higher doses of radiation inhibit this action. It would therefore appear that for tumour production by radiation there is an optimum dosage. Dr. L. D. Parsons has shown that treatment of mice with X-rays or with a carcinogenic agent both result in the deposition of some iron compound giving a Prussian Blue reaction, in the lymphoid tissue. It seems possible that carcinogenic action may be associated with hæmolysis. Lymph glands of mice bearing sarcomas produced by a carcinogenic compound have grown like sarcomas when transplanted into other mice. These changes occur in glands quite irrespective of their proximity to the graft, and the microscopic appearances suggest that they are not metastatic.

Research carried out at the Middlesex Hospital has shown that if rats bearing the Jensen rat sarcoma are cured by treatment with $\mathrm{X}$-rays, they are afterwards immune to that tumour. Partially successful attempts to transfer this immunity have been made by injecting the fluid from irradiated tumours. Injection of the fluid from tumours which have received a dose of X-rays which would eventually cause their disappearance gives some resistance to this tumour in other rats. Work from the J. H. Burn Laboratories at Newcastle-on-Tyne on two rat tumours has shown that the Jensen rat sarcoma is much more radio sensitive than the Walker carcinoma. The Walker carcinoma also is more resistant to heat treatment in vivo, although the two tumours show little difference when heated in vitro. Both types of tumour are killed in vitro by heating for one hour at $45^{\circ}$ or 3 hours at $43.5^{\circ}$.

Experiment has frequently shown that radiation with split doses is more effective than a single exposure. Fresh experiments on mice with epitheliomata at the Mount Vernon Hospital have again confirmed this. Patients at that hospital are treated by the so-called 'stop and go' method in which the tumours are frequently examined and irradiated only when they are considered to be radio sensitive. The intervals between treatments are often as much as three or five weeks.

Investigations on the cancer viruses have not yet led to the isolation of these as chemical entities, but considerable progress has been made in the purification of the Rous chicken sarcoma virus. 